\title{
CHAVE PARA DETERMINAÇÃO DE TREZE CULTIVARES DE CUCURBITA *
}

\author{
LUIZ ANTONIO ROCHELLE**
}

\section{RESUMO}

Baseando-se nas características morfológicas dos frutos e sementes das cultivares pertencentes a três espécies de Cucurbita, elaborou-se uma chave analítica para determiná-las.

Foram utilizadas sementes de polinização controlada.

De cada cultivar estudada foram coletados 30 frutos e 5 sementes por fruto.

Dos frutos e das sementes foram estudadas as seguintes características morfológicas :

Presença ou ausência do pescoço e do bojo do fruto.

Consistência e dilatação do pedúnculo do fruto.

Coloração do epicarpo.

Forma do fruto.

Presença ou ausência de costela ou relevo linear.

Hilo basal da semente.

$\mathrm{O}$ resumo deste trabalho foi enviado a XXVII Reunião Anual da S.B.P.C., realizada em Belo Horizonte (MG), em julho de 1975.

\section{INTRODUÇÃO}

O conhecimento das características morfológicas dos frutos e das sementes, das cultivares pertencentes a espécies de Cucurbita, possibilitou a elaboração de uma chave analítica para determiná-las.

Em um trabalho anterior, no qual, baseando-se na morfologia dos ovários e dos lóbulos do cálice feminino das cultivares, ofereceu-se subsídios para a determinação das mesmas, através de uma outra chave analítica.

* Recebido para publicação em 19/5/76.

* Departlamento de Botânica, ESALQ. - USP. 
O presente trabalho é fundamentado na tese "Descrição Taxonômica de Cultivares de Cucurbita moschata Duchesne, Cucurbita maxima Duchesne e Cucurbita pepo Linneu, apresentada e aprovada na Escola Superior de Agricultura "Luiz de Queiroz".

\section{MATERIAL E METODOS}

Foram estudadas 13 cultivares dentre 3 espécies de Cucurbita. Da espécie Cucurbita moschata Duchesne estudou-se as seguintes cultivares: 'Menina - verde', 'Paca', 'Tatui', 'Menina - amarela', 'Canhão', 'Redonda - de amparo', e 'Menina - creme'. Em Cucurbita maxima Duchesne estudou-se as cultivares 'Exposição', 'Coroa', 'Ovo - de - ganso' e 'Mogango - verde' e para Cucurbita pepo Linneu, considerou-se as cultivares 'Small-sugar' e 'Caserta'.

As sementes utilizadas neste estudo são originadas de polinização controlada.

Colheu-se 30 frutos por cultivar (tendo-se plantado 10 plantas de cada cultivar) e as anotações foram feitas para 5 sementes por fruto.

Estudou-se para os frutos e sementes as seguintes características morfológicas:

Presença ou ausência do pescoço e do bojo do fruto.

Consistência e dilatação do pedúnculo do fruto.

Coloração do epicarpo.

Forma do fruto.

Presença ou ausência de costela ou relevo linear na semente.

Hilo basal da semente.

\section{RESULTADOS: CHAVE PARA DETERMINAÇÃO DE CULTIVARES} DE CUCURBITA

1. Fruto sem uma porção basal (pescoço) e sem uma dilatação terminal (bojo).

2. Semente sem costela ou relevo linear.

3. Hilo basal da semente oblíquo (em relação ao eixo da semente), truncado ou arredondado.

4. Pedúnculo de consistência lenhosa, sulcado e dilatando-se em forma de taça na região de inserção no fruto. 
5. Epicarpo de coloração amarela acentuada, às vezes mais clara e com listas longitudinais, fruto pepônio de forma ovóide ........ 'Tatui'.

3.1 Hilo basal da semente, só oblíquo.

4. Pedúnculo de consistência semi-lenhosa, suavemente sulcado (às vezes quase sem sulcos), não se dilatando na região de inserção no fruto.

5. Epicarpo de coloração amarelo-avermelhado brilhante, fruto pepônio, de forma globosa, com gomos longitudinais salientes, bem achatada e duas concavidades sendo uma mais profunda onde se insere o pedúnculo, a outra mais rasa na face que lhe é oposta ................ 'Exposição'.

6. Epicarpo de coloração verde-acinzentada brilhante, fruto pepônio, globoso, com gomos longitudinais pouco salientes, um tanto achatado, com duas concavidades, sendo uma mais profunda onde insere o pedúnculo, a outra mais rasa na face que lhe é oposta .. 'Coroa'.

7. Epicarpo de coloração cinzenta brilhante, fruto pepônio ovóide, com gomos longitudinais pouco salientes ... 'Ovo-de-ganso'.

8. Epicarpo de coloração verde-acinzentada brilhante, com listas longitudinais mais claras, fruto pepônio de forma elipsóide alongado quase cilíndrico, com gomos longitudinais pouco salientes ........... 'Mogango-verde'.

3.1 Hilo basal da semente arredondado ou truncado.

4. Pedúnculo de consistência lenhosa, sulcado, não se dilatando na região de inserção no fruto.

5. Epicarpo de coloração amarela-clara com manchas verdes, fruto pepônio claviforme ...... 'Caserta'.

4.1 Pecaúnculo de consistência lenhosa, sulcado, quase sempre dilatando-se em forma de taça na região de inserção no fruto.

5.1 Epicarpo de coloração amarela-alaranjada brilhante, fruto pepônio globoso, um tanto achatado, com duas concavidades 
pouco profundas, uma onde se insere o pedúnculo e a outra na face que lhe é oposta .............. 'Small-sugar'.

2.1 Semente com costela ou relevo linear (raro ausente).

3. Hilo basal da semente oblíquo (em relação ao eixo da semente) truncado ou arredondado.

4. Pedúnculo de consistência lenhosa, sulcado, dilatando-se em forma de taça na região de inserção no fruto.

5. Epicarpo de coloração amarela intensa, fruto pepônio globoso, com duas concavidades bem rasas, uma na inserção do pedúnculo e a outra na região que lhe é oposta, com gomos pouco salientes ............ 'Redonda-de-amparo'.

6. Epicarpo de coloração castanha com listas verde-escuras, fruto pepônio de forma elipsóide com o eixo maior no prolongamento do pedúnculo ............ 'Paca'.

1.1 Fruto com uma porção basal (pescoço) recurvada ou não, e uma dilatação terminal (bojo).

2. Semente com costela ou relevo linear.

3. Hilo basal de semente oblíquo (em relação ao eixo-semente), truncado ou arredondado.

4. Pedúnculo de consistência lenhosa, sulcado, dilatando-se em forma de taça na região de inserção no fruto.

5. Epicarpo de coloração castanha escura, com listas verde-escuras, fruto pepônio cilíndrico, recurvado (pescoço) ............ .................... 'Menina-verde'.

6. Epicarpo de coloração amarela, fruto pepônio cilíndrico, recurvado (pescoço) $\ldots \ldots \ldots \ldots$ 'Menina-amarela'.

7. Epicarpo de coloração creme, fruto pepônio cilíndrico recurvado (pescoço) ......... 'Menina-creme'. 
8. Epicarpo de coloração castanha, variegada de verde-escura, fruto pepônio cilíndrico, dilatando-se na outra extremidade......... 'Canhão' .

\section{SUMMARY}

\section{KEY TO DETERMINE CULTIVARS OF THREE SPECIES OF CUCURBITA}

An analytic key was done based upon morphological characteristics of fruits and seeds of 13 cultivars belonging to 3 species to identify them. It was used seeds from controlled pollination. Is was considered: fruit-shape, epicarp color, perluncle dilatation and consistence, seed-hilum and longitudinal lineal salience.

\section{LITERATURA CITADA}

CASTETTER, E.F. \& ERWIN, A.T., 1927. A Systematic study of squashes and pumpkins. Iowa. p. 107-135.

ROCHELLE, L.A., 1973 - Descrição Taxonômica de Cultivares de Cucurbita moschata Duchesne. Anais da E.S.A. "Luiz de Queiroz", 30: 129-161.

ROCHELLE, L.A., 1974 - Descrição Taxonômica de Cultivares de Cucurbita maxima Duchesne, Cucurbita pepo Linneu. Anais da E.S.A. "Luiz de Queiroz", 31: 667-700.

RUSSEL, P., 1924 - Identification of the commonly cultivated species of Cucurbita by means of seed characters. Jour. Wash. Acad. Sci. 14: 265-269. 
